Faculdade de Ciências Econômicas UFRGS
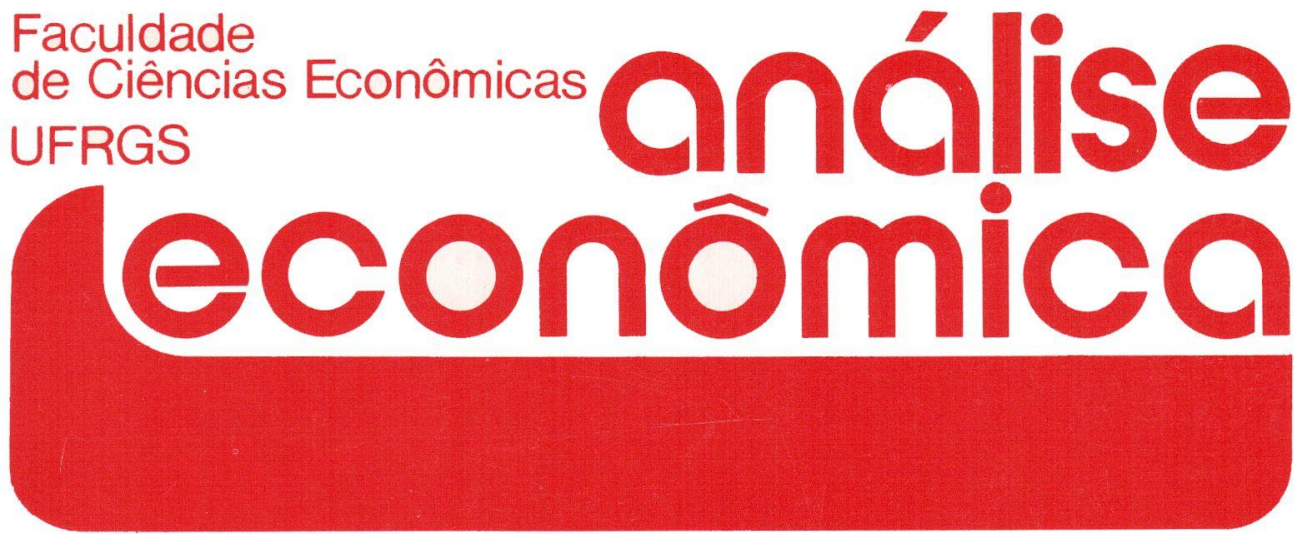

- INDEXAÇĀo SALARIAL: UMA ABORDAGEM MACROECONÓMICA Jo Anna Grav

- AJUSTE NO EMPREGO E PRODUTIVIDADE NA DECADA DE OITENTA

Carlos Antônio Luque José Paulo Zeeteno Chahad

- O CONSUMIDOR KEYNESIANO Marcelo Córtes Neri

- HETEROGENEIDADE DO TRABALHO E TAXA DE LUCRO EM MARX

Francisco Cribari Neto

- ECONOMIAS DE ESCALA: UMA REVISĀO Jesiel de Marco Gomes

- Concentraçấo bancária no BRASIL

Marcelo Resende

- NOYOS RUMOS PARA O SETOR ELETRICO NO BRASIL

Adriano Pires Rodrigues

Eduardo da Cunha Vianna

- OFERTA E DEMANDA DE FRANGO DE CORTE NO BRASIL

Narciso Gonçalves de Castro et alii

- ANÁLISE ECONÔMICA DA IRRIGAÇÃo DO MILHO

Lúcia M Schirmer

Juvir Luiz Mattuella

- REFLORESTAMENTO NO BRASIL. Carlos José Caetano Bacha

- ESCOLHA DE TECNOLOGIA EM ESTRUTURA DE PRINCIPAL AGENTE Kyle D. Kauffma:

- A QUESTÁo DEMOGRÁfica e A PRAXEOLOGIA

Anton Karl Biedermann et alii
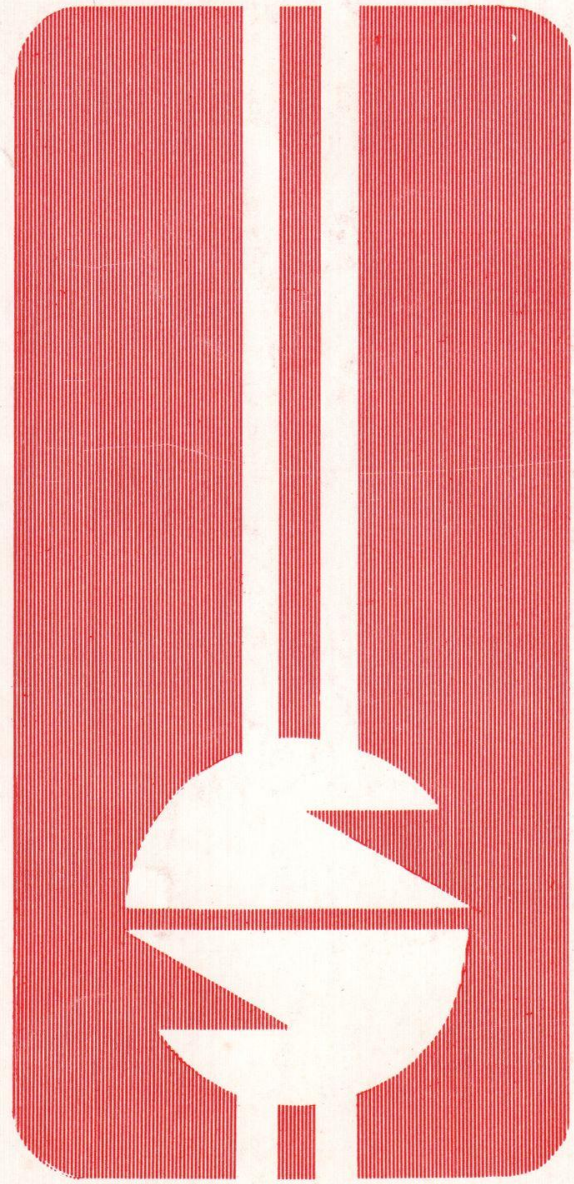
UNIVERSIDADE FEDERAL DO RIO GRANDE DO SUL

Reitor: Prof. Tuiskon Dick

FACULDADE DE CIÉNCIAS ECONÔMICAS

Diretora: Prof ${ }^{\text {a }}$ Yeda Rorato Crusius.

CENTRO DE ESTUDOS E PESQUISAS ECONÔMICAS

Diretor: Reinaldo Ignacio Adams

DEPARTAMENTO DE CIÉNCIAS ECONÔMICAS

Chefe: Prof. Fernando Ferrari Filho

CURSO DE POS-GRADUAÇÄO EM ECONOMIA

Coordenador: Prof. Nali de Jesus de Souza

CURSO DE PÓS-GRADUAÇĀO EM ECONOMIA RURAL

Coordenador: Prof. Atos Freitas Grawunder

CONSELHO EDITORIAL: Achyles Barcelos da Costa, Aray Miguel Feldens, Atos Freitas Grawunder, Carlos Augusto Crusius, Ernani Hickmann, João Rogério Sanson, Juvir Luiz Mattuella, Maria Imilda da Costa e Silva, Nali de Jesus de Souza, Nuno Renan Lopes de Figueiredo Pinto, Otilia Beatriz Kroeff Carrion, Otto Guilherme Konzen, Paulo Alexandre Spohr, Pedro Cezar Dutra Fonseca, Reinaldo Ignacio Adams, Roberto Camps Moraes, Valter José Stülp, Yeda Rorato Crusius, David Garlow (Wharton Econometrics Forecasts Association, E.U.A.), Edgar Augusto Lanzer (UFSC), Eleutério F.S. Prado (USF), Fernando Holanda Barbosa (FGV/RJ), Gustavo Franco (PUC/RJ), Joaquim Pinto de Andrade (UnB), Juan H. Moldau (USP), Werner Baer (Univ. de Illinois, E.U.A.).

COMISSĀO EDITORIAL: Atos Freitas Grawunder, Pedro Cezar Dutra Fonseca, Reinaldo Ignacio Adams e Roberto Camps Moraes.

EDITOR: Nali de Jesus de Souza

SECRETARIA: Maria Ivone de Mello (normalização), Vanete Ricacheski (revisão de textos).

FUNDADOR: Prof. Antônio Carlos Santos Rosa

Os materiais publicados na revista Análise Econômica são de exclusiva responsabilidade dos autores. É permitida a reprodução total ou parcial dos trabalhos, desde que seja citada a fonte.

Aceita-se permuta com revistas congêneres. Aceitam-se, também, livros para divulgação, elaboração de resenhas ou recenșões.

Toda correspondência, material para publicação, assinaturas e - permutas devem ser dirigidos ao seguinte destinatário:

\section{PROF. NALI DE JESUS DE SOUZA}

Revista Análise Econômica

Av. João Pessoa, 52

CEP 90040-000 - PORTO ALEGRE (RS), BRASIL

Telefones: (051) 228-1633 - 224-6024 ramais 3440 e 3348

Fax: (051) 225-1067 


\title{
A QUESTÃo DEMOGRÁFICA E A PRAXEOLOGIA ${ }^{1}$
}

\author{
Anton Karl Biedermann2 \\ Alfredo Marcolin Peringer ${ }^{3}$ \\ Jose Paulo Soares Martins4 \\ Paulo Cesar Flores 5
}

\section{SINOPSE}

O trabalho analisa a questão demografica à luz das teses de Thomas Malthus e do Clube de Roma e reconhece a verdade inconteste de ambas as teorias. Concorda que há uma lei natural biológica que impede que haja sobrevida na terra sem o alimento básico para a subsisténcia humana. $O$ uso indiscriminado dos recursos naturais năo renováveis, por sua vez, pode levar à sua exauståo que, junto com a degradação do meio ambiente, fruto de uma industrializaçăo suja, tambem podem impedir o homem de contar com os meios necessários à sua sobrevivência. Todavia, o estudo da praxeologia, ciência da açăo humana, nos garante que nunca chegaremos, num contexto mundial, aos limites malthusianos ou aos do Clube de Roma. Os desequilibrios entre populaçăo e alimento, hoje existentes em algumas regiōes do mundo, șá frutos da desfiguraç̆̃̂́ da açăo humana, provocada por subsídios materiais internos e externos, fonte de estfmulo à procriação indevida. A revogaçăo desses subsídios e de outros estímulos à procriação e uma condição essencial à vida do homem na terra.

\section{A TEORIA MALTHUSIANA DO CRESCIMENTO DA POPULAÇÃO}

\subsection{Os Princrpios Malthusianos}

Thomas Robert Malthus (1766-1834) foi o primeiro escritor a colocar, tacitamente, no seu Essay on the Principle of Population, que a população mundial iria sempre crescer além dos meios necessários à sua subsistência. Seu trabalho não partiu do Homem em si, mas de um estu-

1 Este trabalho, coordenado por Alfredo M. Peringer, \& fruto dos debates promovidos pela Federação das Associaçбos Comerciais do Rio Grande do Sul - FEDERASUL. sobre crescimento demografico.

2 Presidente da FEDERASUL.

3 Consultor İconరీmico da FEDERASUL e Mestre em Finanças pela Michigan State University.

4 Diretor Executivo da FEDERASUL.

5 Assessor de Imprensa da FEDERÁSUL.

\begin{tabular}{|l|l|l|l|l|}
\hline ANÁLISE ECONÔMICA & ANO 10 & No 17 & MARÇO/92 & P.163-184 \\
\hline
\end{tabular}


do de como viviam as demais especies animais e vegetais na terra. Descobriu que se os germes pudessem desenvolver-se, livremente, encheriam muitos mundos no decorrer dos anos. O mesmo princípio era válido para as plantas. Citou, contudo, que uma "lei natural" impedia que tanto os animais, quanto as plantas, viessem a se desenvolver ilimitadamente. O limite não ia além da capacidade deles se auto-alimentarem. Teria, por outro lado, de também ser válido para o homem. Dizia que era uma lei natural da qual a espécie humana não poderia escapar.

A tese de Malthus enfocava que a verificação da lei natural para o elemento humano era uma questão de tempo. Observou, em 1798, que a população tendia a dobrar a cada 25 anos nas colónias da América, onde os recursos eram abundantes, e postulou uma tendência universal que a produção de alimentos crescia em progressão aritmética e a população em progressão geométrica. Cedo ou tarde, portanto, a humanidade encontraria o seu limite e, além dele, não teria meios de subsistir. Af, então, o prinć́pio válido para as espécies vegetais e demais espécies animais tamberm seria válido para o Homem. A recomendação fatal, portan$\omega$, era a de se reduzir o crescimento populacional, adequando-o às possibilidades de crescimento da produção dos alimentos. Essa recomendação era feita em nome da felicidade do homem na terra e em nome dessa felicidade, o homem deveria obedecer.

\subsection{A Verificação das Teorias Malthusianas}

A abundância de terras férteis proporcionou, no passado, aos indivíduos, manter um certo nível de produtividade, apenas expandindo as áreas agrícolas e usando processos de produçāo rudimentares. A partir de 1180, contudo, as terras férteis começaram, lentamente, a esgotaremse e, com elas, as alternativas de aumento da produção. Passou-se a cultivar terras menos nobres. De 1180 a 1300, começou uma fase de "rendimentos decrescentes", de que Malthus nos falava, ou seja, a produção per capita decrescia e, com ela, decrescia o padrão de vida da população. A fome e as doenças, facilitadas pela desnutrição, eram uma constante. A ação da mãe natureza fazia o seu papel: matava, provocando o retorno do equilfbrio entre a população e a produção de alimentos.

Nos anos entre 1315 e 1317, houve grande reduçāo populacional na Europa Ocidental, provocada pela fome e pelas doenças. Um percentual muito grande de mortes tambem ocorreu entre os anos de 1347 a 1351, perfodo no qual uma doença fatal, denominada de "Peste Negra", matou milhares de pessoas (1/3 da populaçã̄o européia). Nestes anos, as pragas e as pestes eram um lugar comum no mundo.De 1450 e 1680, houve novos ciclos de doenças e de mortes, provocadas, principalmente, pela desnutrição, que enfraquecia as pessoas, tornando-as presas fáceis 
de doenças e de pestes. Surtos de crescimento populacional, como os dos anos de 1470 a 1580, eram sempre seguidos de declínio, como os de 1580 a 1680.

Um fato muito importante, e que tem passado despercebido nas literaturas sobre demografia, é que, nas épocas de fome, também havia redução das taxas de natalidade, retornando à fecundidade anterior so depois do retorno das perspectivas de abundância. Com o passar dos anos, porém, a tecnologia desenvolvia novas maneiras de se aumentar a produtividade da terra. As dificuldades jâ não eram tão grandes ao homem. $O$ avanço tecnológico, as descobertas de vacinas preventivas e o desenvolvimento da medicina, reduziam as taxas de mortalidade. Com isso, conseguia-se superar, ou transferir-se para mais adiante, as leis naturais malthusianas. A população expandia as fronteiras agricolas e mantinha a produtividade, cultivando terras favorecidas. Assim, a colonizção do mundo manteve-se por muitos séculos.

De 1750 em diante, a população mundial cresceu continuamente. Malthus nasceu em 1766. Teve a experiência de seus antepassados que conviveram com a fome e com as doenças. Diferente deles, porém, que conviveram com os fatores de ajuste e de equilfbrio das quantidades de pessoas existentes, em relação às disponibilidades de alimentos, Malthus não visualizava nenhum equilibrio, quer sobre a taxa de fertilidade, quer da de mortalidade. Acontece que a ciência e o conhecimento humano tornaram-se aliados do homem, desenvolvendo neles imunidades natu-: rais, que iam enfraquecendo as causas das n,ortes. A fome, as pestes e as doenças, ao menos de uma maneira geral, deram lugar à äbundância e à saúde.

Com isso, a população mundial, que em 1750 era de 730 milhões de habitantes, pulou para 2,5 bilhões em 1830 e, hoje, existem mais de 5 bilhões de pessoas habitando a terra. Embora a população cresça a taxas elevadas, sem precedentes, a produção de alimentos e dos demais bens e serviços, crescem mais ainda. Os ciclos dos desastres malthusianos têm sido vencidos... ao menos por ora. Isso não invalida, porém, as suas fundamentais teses no plano biológico: o crescimento do homem encontra-se limitado não só pela produção de alimentos, como pela produção dos demais bens e serviços essenciais à sua sobrevivência. Nada é mais verdadeiro do que essas afirmações... no terreno biologico.

\section{O FATOR ECOLÓGICO}

A ecologia é o estudo do bomem, e dos demais seres vivos, em relação aos ecossistemas naturais da terra. ( 1 homem encontra-se no centro de todos esses ecossistemas. O estudo do clima, do njeio ambit:nte e dos fatores cue agridem esse meio ambiente, visam a melhorar a qualidade da vida preserte e futura do homem. As preccupaçōes, por exemplo, 
com o elevado crescimento populacional cos países mais pobres são furdamentadas nas dificuldades cada vez maiores desses países em trair bens e serviços do setor rural e incustrial para alimentar, vestir, dar abrigo, educar e divertir a stá população. O nedo é que, dado o alto e desordenado crescimento populacional, a terre não consiga suprir as exigências humanas.

Nada mais certo do que também afirmar que o bem-estar da população, ou a sua própria sobrevivência, dependa do fator terra. A poluição, e as demais degradações do meio ambiente, podem provocar o esgotamento dos insumos utilizados nos processos de fabricação. Dessas idéias, surgiu um grande envolvimento ecológico, preocupado em adequar o crescimento populacional aos ecossistemas regionais. Surgiram inúmeros estudos sobre clima, química do solo, fauna, ciclo hídrico e sobre a influência desses fatores na vida humana e da vida humana nes. ses fatores. $O$ ar que se respira, a água que se bebe, a comida que se produz são fatores afetados pelo homem ao habitar a terra

O problema consiste, segundo os ecologistas, em que, para obter os alimentos que consomem, os individuos transformam os ecossistemas estáveis e complexos em ecossistemas simples e unitários, com enormes prejurzos à cadeia ecológica. Exemplo disso são as monoculturas de arroz, trigo e soja, ou a criação de animais para o consumo da carne, do leite e da lã. Há uma conversão de florestas (ecossistemas complexos), em campos agricolas ou de pastagens (ecossistemas simples), que agem contra o meio ambiente. Os aspectos nocivos tambem podem ser vistos pelo uso dos fosfatos, formadores de algas, e dos pesticidas, que provocam doenças e pestes, sem falar nas erosões, que empobrecem a terra e causam o assoreamento do rios e dos lagos e que limita a vida do Homem na terra. Quando a população ultrapassa os limites impostos pelo meio ambiente, aparecem as doenças, as pestes e a fome, provocadas por uma grande interação de fatores em cadeia. Esses fatores agem como protetores dos ecossistemas regionais e condicionam a adaptabilidade genética da população às condições ambientais.

\section{O CLUBE DE ROMA}

\subsection{O Modelo}

Coube a um grupo de estudiosos do Massachusetts Institute of Tecnolgy (MIT), dos Estados Unidos, liderados por Dennis L. Meadows, levar adiante as teses de Malthus. O estudo foi patrocinado pelo "Clube de Roma" e publicado no livro Os Limites do Crescimento ou Os Predicamentos da Humanidade. Resumiu-se num modelo ma- 
temático que inter-relaciona o crescimento populacional à degradação do meio ambiente, concluindo que a interação dos indivfduos, com esses fatores, vão impedir que o homem possa contar, em futuro próximo, com os meios necessários à sua sobrevivência.

$O$ Clube de Roma utilizou um modelo matemático exponencial simples. Os modelos podem ser lineares ou exponenciais. Nos lineares, as variáveis crescem em quantidades determinadas (cruzeiros, alturas, etc.). Uma criança, por exemplo, cresce " $x$ " centrmetros ao ano. Nos exponenciais, o crescimento incide em percentuais, sobre uma base. Exemplo desse modelo são os cálculos do montante de dinheiro, colocado a juros compostos anuais, num determinado perfodo de tempo.

O modelo do Clube de Roma, assim, ex exponencial. Trabalha com industrialização acelerada, rápido crescimento populacional, larga desnutrição, exaustão dos recursos não renováveis e alta depreciação do meio ambiente, num universo de 100 anos. De acordo com os próprios pesquisadores, é um modelo imperfeito, supersimplificado e incompleto. As pressuposições, entretanto, encontram-se abertas no modelo, podendo serem alteradas, inclứdas novas variáveis e/ou se fazer modificações diversas, com vistas ao seu melhoramento.

No modelo do Clube de Roma, em 1650 a população mundial era de 500 milhões de habitantes. Crescia a uma taxa de $0,5 \%$ ao ano. Dobrava, portanto, a cada 250 anos. Em 1970, a população mundial era de 3,6 bilhões de habitantes e a taxa de crescimento de $2,1 \%$ e dobrava a cada 33 anos. Não cabe a menor dúvida de que, com um crescimento exponencial da população e um crescimento aritmético ou linear dos alimentos, a vida animal na terra teria um fim. O único problema $\epsilon$ que o modelo não incorpora, dinamicamente, as ações e interações do homem em cada estágio do modelo.

\subsection{A Filosofia}

O Clube de Roma integra as teses de Malthus com as dos ecologistas. Com isso, deu nova dimensão às teses malthusianas. A análise saiu da relação entre crescimento populacional e produção de alimentos e passou a incluir a exaustão dos recursos naturais. Aparentemente, o homem venceu as teses malthusianas. $\mathrm{Na}$ luta pela sobrevivência, desenvolveu tecnologias avançadas, conseguindo multiplicar a produção de alimentos, presente e futura. A ensilagem, os novos métodos de conservação e a produção em massa têm conseguido satisfazer a fome da população presente e reservar grandes quantidades de alimentos para a população futura. No modelo do Clube de Roma, porern, e o avanço tecnológico desenfreado que vai limitar a vida do homem na terra.

No trabalho do Clube de Roma, cinco fatores são determinantes 
nos limites do crescimento de nosso planeta: a população, a produção agricola, a produção industrial, os recursos naturais e a poluição. Cabe a esses fatores a responsabilidade pelos grandes problemas dos individuos, como a pobreza, a degradação do meio ambiente, a perda da fé nas instituições, a incontrolável expansão urbana, a insegurança no emprego, a alienação dos jovens, a rejeição dos valores tradicionais, a inflação e outros desajustes econômico-sociais. Todos eles ocorrem em determinado grau em todos os pafses. A interação do crescimento populacional, com o crescimento da produção, causa a poluição e a exaustão dos recursos naturais fixos.

Passou, assim, a levar em conta a velocidade de depreciação dos recursos naturais. Não deixa, na verdade, de ser uma tese malthusiana, mas de forma mais sofisticada. A necessidade de manter um contingente populacional cada vez maior vai exaurir os recursos naturais não renováveis, como ó petróleo, o carvão betuminoso, o aço, a energia elétrica natural, o sal, entre outros.

Transferiu a ênfase antes colocada no crescimento populacional, para o crescimento do consumo per capita. A mudança de enfoque analítico e fundamental para se localizar o problema que passa, com isso, a ser alçada dos parses ricos, onde o consumo per capita é bem maior do que o dos parses pobres. A distinção e crucial. Para Malthus, o problema era de crescimento populacional, em relação ao crescimento dos alimentos. Tinha-se de aumentar a produção de alimentos ou reduzir o crescimento populacional para resolvê-lo. Para o Clube de Roma, não, pois o problema consiste exatamente no crescimento acelerado dos meios de produção, em desproporção ao meio ambiente. Não se consegue mais resolver o problema pelo aumento da produção, mas apenas pela redução do crescimento populacional.

O trabalho enfoca que, em 1960, o consumo per capita de petróleo nos Estados Unidos era de 700 galōes ao ano, usado na industrialização, aquecimento interno e nos autmóveis; do carvão betuminoso, 4000 libras (eletricidade/equivalentes); do aço, 1100 libras; sal, 300 libras, sendo que uma parte muito pequena para temperos. Com base no consumo per capita, estimou-se que as reservas de alumínio acabariam em 31 anos; as de cobre, em 21; as de chumbo, em 21; as de mercúrio, em 13; as de gás natural, em 22 e as de zinco, em 18 anos. Como a terra e os recursos naturais são fixos, a elevada taxa de consumo per capita dos parses ricos em breve iria exaurir os recursos naturais e tornaria insuficiente a produção de alimentos, donde há de vir a fome, as pestes, as doenças e... as mortes. Advogam, por isso, não só a redução do crescimento populacional, como a do crescimento económico.

Caso isso não aconteça, a humanidade vai chegar a uma nova era de fome em massa. O fim do perdularismo e da extravagência é condi- 
ção necessária para a sobrevivência do homem na terra. Insistem que a dimensão da terra e limitada e cedo ou tarde vão acabar os recursos naturais não renováveis. $O$ homem vai extrair todo o petróleo, o alumínio, o cobre, o chumbo, o mercúrio, o gás natural, o zinco, entre outros. Se não for por isso, ou junto com isso, é a poluição que vai impedir que o homem aumente a produção de alimentos da Terra.

Como evidência de suas teses, o Clube de Roma aponta que o consumo de grãos vem crescendo a taxa de $2,5 \%$ ao ano, levando a uma redução dramática dos estoques de alimentos nos últimos anos. $\mathrm{O}$ mundo tinha estoques para mais de três meses em 1960 e hoje andam ao redor de vinte dias. Chegou-se a cogitar a criação de um Banco de Alimentos no mundo. Fala-se na modernização da agricultura dos parses pobres; na intensificação das pesquisas agrícolas; na conservação dos alimentos: na construção e no aperfeiçoamento dos silos.

As previsões do Clube de Roma, contudo, não se verificaram e, provavelmente, não se vão verificar. Antes disso, os preços aumentam e limitam o uso desses recursos ou promovem-se novas descobertas.

\subsection{A Escassez e o Crescimento Populacional}

A primeira explicação para não ter havido a exaustão dos recursos naturais não renováveis ê a de que a escassez é uma questão de preços. Os preços aumentam proporcionalmente à medida que os estoques se reduzem, diminuindo o consumo e evitando a exaustão. Os altos preços também favorecem a substituição dos produtos por outros de menor preço. A tecnologia, ademais, estimula a criação de novos produtos, lançados para substituir os antigos, desenvolvendo-se tamberm novas formas de produção. Por isso, o volume de reservas dos minerais, "em exaustão", continua aproximadamente o mesmo. Os avanços tecnologicos, por outro lado, têm proporcionado aumentos da oferta superiores à demanda, apesar do crescimento da procura. Tem havido, inclusive, reduções dos custos e a produtividade tem crescido em índices superiores ao crescimento da população.

Uma segunda explicação, ê a de que há na crostra terrestre uma massa homogênea de minerais, distriburdas uniformemente. Cada milha cúbica de rocha teria um bilhão de toneladas de alumínio, 625 milhōes de ferro, 650 mil de cobre, $185 \mathrm{mil}$ de chumbo e $60 \mathrm{mil}$ de ouro (North \& Miller, p.11).

$\mathrm{Na}$ verdade, ate aqui, tanto os predicamentos da teoria malthusiana, quanto os do Clube de Roma, têm sido evitados, principalmente pelo desenvolvimento tecnologico e pela descoberta de novas formas de se fazer as coisas. A continuidade, porem, do sucesso o homem sobre tais teses vai depender: a) da capacidade dele continuar descobrindo novas formas tecnologicas que superem a "Lei dos Rendimentos Decrescentes"; b) se 
a tecnologia do homem não provocar exaustão do meio ambiente; e c) das mudanças das taxas de fertilidade e das de mortalidade.

No decorrer dos anos tivemos muitas crises, como a da carne e a da soja na Segunda Guerra Mundial, e a do petroleo, em 1973. Todas as crises, porém, ora foram resultantes da natureza (clima, pragas, etc.), ora da ação do homem, na promoção de cartéis e de outros tipos de monopólios. O sistema de preços, todavia, tem entrado em cena e o problema E logo resolvido. Temos de evitar, de toda maneira, advogar políticas que redundem em intrusão do governo no mercado, quando o problema pode ser resolvido sem ele. A atuação governamental, quando necessária, não pode ser atuante, mas orientadora, principalmente na forma de estímulos e não operacional.

\section{A TAXA DE FECUNDIDADE E A TAXA DE MORTALIDADE}

\subsection{Historico}

O estudo do crescimento demográfico pode melhor ser compreendido quando se analisa se o desequilibrio encontra-se na taxa de fecundidade ou na de mortalidade. Mencionamos que a queda da taxa de mortalidade deveu-se ao aprimoramento das condições sanitárias, do avanço tecnológico e do aperfeiçoamento da medicina, principalmente nas populações infantil e idosa.

Em sécuos passados, nos períodos de fome, pragas e pestes, os casamentos se reduziam. Chegou-se a praticar, inclusive, o infanticídio. As formas modernas contraceptivas, contudo, aliadas às práticas de aborto legal e ilegal, tornaram a fertilidade uma ação deliberada dos indivíduos.

\subsection{As Grandes Metrópoles}

O baixo padrão de vida do campo faz com que grande contingente de pessoas "tentem a sorte" nas cidades. Exercem uma pressão crescente sobre os investimentos de infra-estrutura, tais como habitação, educação, saúde, água, energia, esgoto, calçamento, entre outros, exigindo altos gastos dos governos municipais. A pressão maior é sobre as grandes metrópoles. Alem delas abrigarem o seu próprio crescimento populacional, abrigam os imigrantes, que incham as suas redondezas, formando um cinturão de necessitados em sua volta, com todos problemas resultantes.

Nos países em desenvolvimento, ainda há um elevado percentual de pessoas trabalhando no campo. No Brasil, paŕs em desenvolvimento, em 1990 esse percentual era de $24 \%$ (população urbana de 114.699 mi- 
lhôes e a rural de 35.669). Em 1995, o IBGE estima que a população seja de 165.083 milhões de habitantes e que more $22 \%$ na área rural.

Um estudo do "Comitê da Crise Populacional", com sede em Washington, concluiu que, no inf́cio deste século, $90 \%$ da população mundial vivia nas zonas rurais e apenas $10 \%$ nos centros urbanos. Até o final da década de 90, porém, o percentual dos centros urbanos vai-se elevar para $50 \%$, exigindo vultosos recursos de capital e de matérias-primas. O problema, para os braileiros, e que das 100 grandes cidades analisadas no mundo pelo Comitê, 21 delas, com cresciment c superior a $3 \%$ ao ano, eram dos parses pobres e três encontravam-se no Brasil): São Paulo (crescimento de 3,97\%), Belo Horizonte $(3,85 \%$ ) e Porto Alegre $(3,23 \%)$. Perdem, entretanto, para Lagos $(5,86 \%)$, capital da Nigeria, cidade que mais cresce no mundo.

Esse fenômeno é próprio dos países em desenvolvimento e é movido pelas melhores oportunidades de emprego que se oferecem nas cidades. No Brasil, porém, ele tem sido estimulado por legislaçōes "bern-intencionadas". Por exemplo, com a pretensão de ajudar os trabalhadores do campo, o Governo João Goulart criou o Estatuto do Trabalhador Rural, com uma série de custos adicionais à mão-de-obra rural, causando grande desemprego no campo e levando os desempregados a bater nas cidades, fazendo aumentar os seus "cinturões" de pobreza.

O problema maior, contudo, ainda está por vir, com as falácias da nova Constituição Brasileira ao equiparar o salário mínimo do trabalhador rural ao urbano, podendo-se prever, com a implementação das normas, um grande desemprego no campo e um novo "inchaço" das cidades, com as graves conseqüências que disso resulta.

\subsection{A Questāo Financeira como Estf́mulo ao Crescimento Demografico}

Nas civilizaçōes mais adiantadas, as decisões de ter ou não ter filhos têm sido uma ação racional dos indivíduos, vinculadas às perspectivas futuras, principalmente as econômicas.

No setor agrícola, as famílias são maiores, não pelo prazer de criar filhos, mas por decisões econômicas. Os filhos, a partir de sete ou oito anos, são uma fonte de trabalho. Apresentam-se, também, como uma forma de seguridade para os velhos, que podem contar com eles no futuro para o seu sustento.

Nos países adiantados, o renômeno migratório do campo para as cidades já ocorreu. Nos Estados Unidos, por exemplo, $90 \%$ da população trabalhava na agricultura na época da revolução americana. Em 1911 , apenas $22 \%$. Atualmente, menos de $4 \%$ da população americana trabalha no campo. O próprio número absoluto de americanos que mora- 
va no setor rural foi reduzido. Era de 32,1 milhōes de pessoas em 1910 e, em 1967, baixou para 11 milhōes. Nos centros urbanos, entretanto, os filhos são uma grande fonte de despesas e não de ganhos. Afora a alegria e a satisfação pessoal, implicam apenas gastos de custeio e não de investimentos.

Em 1975, o "Institute of Life Insurance" dos Estados Unidos calculou que o custo de uma criança, até aos dezoito anos de idade naquele Paŕs, era de US $\$ 45.000,00$ despedidos em alimentação, vestuário, estudo, saúde, etc. Não se encontra inclứdo, nesse valor, o custo de oportunidade de cuidar dos filhos, dado pelas horas despendidas dos pais nessa tarefa, quando poderiam estar trabalhando em outro lugar. Como o custo financeiro $e$ um dos principais fatores que induz à redução de filhos nas grandes cidades, a tendência sempre foi a de se reduzir ainda mais as taxas de natalidade, devido ao aumento dos custos de criação dos filhos no decorrer dos tempos. Isso explica, em grande parte, a baixa taxa de fertilidade nos parses desenvolvidos.

O fator econômico, portanto, é essencial como limitador da taxa de fecundidade. Assim, que os filhos passam a ser custos, em vez de investimentos, a taxa de fecundidade cai. Hayek, no seu último livro Fatal Conceit, coloca que o fenômeno migratónio do campo para as cidades não elimina, de imediato, a taxa de fecundidade. Os individuos continuam a manter as tradiçóes e os costumes do campo. Demora um pouco, assim, a adaptação deles às normas e costumes da cidade ou da economia de mercado. É a economia de mercado ou catalática, conforme define Hayek, que limita a taxa de fecundidade.

\section{AS PRETENSAS FALHAS PRAXEOLÓGICAS}

\subsection{A Potencialidade dos Indivíduos}

A Lei Natural de Malthus é uma verdade biológica da qual nenhum ser vivo, seja animal ou vegetal, pode escapar. Sem alimentos, ninguem consegue sobreviver. Não se pode negar, também, as teses do Clube de Roma de que se deve viver em harmonia com o meio ambiente. Até há poucos séculos, o excesso populacional, quando não era minimizado pelas guerras, o era pelas doenças, pestes e forne. Esses fatores inibiam o crescimento e reduziam a carga de extraçāo de alimentos da terra. $O$ homem, contudo evoluiu. Soube tirar proveito da inteligência superior e desenvolver meios de extrair da terra os suprimentos para as suas necessidades físicas e psicológicas. Foi mais além, criou uma infra-estrutura de bens e serviços que the possibilitou não só se automanter, como manter um grande número de animais domésticos, de sua estimação. Mas não se iludam, o ser homem seria o primeiro a fazer desse tipo de animal 
doméstico a sua próxima refeição, em caso de extrema necessidade. Não o faz, porque não sente necessidade.

$O$ que se quer dizer $e$ que a lei biológica de Malthus aplica-se perfeitamente não sర aos animais irracionais, como tambem ao homem, ser racional. Malthus nos dizia que os animais param de procriar quando lhes faltam alimentos. O mesmo acontece com outras formas de vida (germes, plantas, etc.). Acreditava, contudo, que a lei não era válida para o elemento humano. Malthus, porém, estava errado. A lei também válida para ele. Tanto $\varepsilon$ assim, que inventou inúmeros meios de dissociar o prazer da procriação. Hoje os casais, quando não desejam fillhos, mantêm relações sexuais apenas nos dias não-férteis ou valem-se das inúmeras variedades contraceptivas.

Fica, entretanto, uma questão intrigante. Por que há excesso populacional, ao menos aparente, em alguns paŕses e regióes do mundo? Por exemplo, em grande parte dos pafses africanos, a quantidade de alimentos disponfveis encontra-se bastante aquém da que seria necessária para alimentar as suas populações, conforme quadro abaixo:

\section{Tabela 1 - ALIMENTOS NECESSÁRIOS E DISPONÍVEIS PARA O ATENDIMENTO DA POPULAÇĀO DE PAÍSES SELECIONADOS}

\begin{tabular}{lccc}
\hline PAÍsES & $\begin{array}{c}\text { POPULAÇÃO } \\
\text { (milhōes) }\end{array}$ & $\begin{array}{c}\text { ALIMENTOS } \\
\text { NECESSÁRIOS } \\
\text { (toneladas) }\end{array}$ & $\begin{array}{c}\text { ALIMENTOS } \\
\text { DISPONÍVEIS } \\
\text { (toneladas) }\end{array}$ \\
\hline Etiópia & 48,0 & 1.350 & 803 \\
Sudão & 23,8 & 1.200 & 563 \\
Moçambique & 15,0 & 281 & 130 \\
Somália & 5,9 & 130 & 9 \\
Arggola & 9,5 & 109 & 54 \\
\hline
\end{tabular}

Fonte: Banco Mundial (1989).

Os parses necessitados acima teriam de adequar a quantidade de habitantes em relação à quantidade de alimentos disponfveis. A Etiópia não poderia ter gerado cerca de $41 \%$ de seus habitantes, o Sudão, $53 \%$, Moçambique, $54 \%$, a Somália, $93 \%$ e Angola, $50 \%$.

A ciência econômica, contudo, nos diz que a ação humana, agindo livremente e sem intervenção, teria de ter adequado a população à quantidade de alimentos existentes, da mesma forma que os animais o fazem. Embora pareça que os postulados econômicos estariam errados, exigindo 
sua reformulação, esse não é o caso. O problema encontra-se na inversão da aferição dos valores e na colocação dos conflitos ditos "morais", acima dos conflitos econômicos. Assuntos que deveriam ser resolvidos pela ciência econômica, são resolvidos pelo que se passou a definir de padrões éticos, padrōes morais, padróes religiosos e outros do gênero. Os parses adiantados, na boa intenção de resolver o problema da fome nos parses pobres, subvenciona-os, subsidia-os, fazendo farta distribuição gratuita de alimentos que, se, por um lado, ameniza-lhes a fome a curto prazo, por outro, comete o erro de gerar perspectivas de vida, independentemente do trabalho produtivo, agravando-lhes o problema a longo prazo.

Sem interferência, essas populaçōes nāo seriam geradas. Elas só existiriam se o aumento populacional fosse acompanhado pelo aumento da produtividade, desenvolvido através do uso de melhores tecnologias e/ou do melhor uso do solo e não por subsídios artificiais, provenientes de fora de suas regiões. Não há nada a temer do crescimento populacional, desde que venha acompanhado do aumento da produtividade. Fredrich von Hayek diz que "moralmente, não temos o menor direito de impedir o crescimento populacional em qualquer parte do mundo. Da mesma forma, não temos o menor direito de subvencionar as populações carentes" (Hayek, 1990, p.120). O fato é que há poucas perspectivas de vida em determinadas regiões carentes do mundo. Sem assistência externa, as populaçōes residentes nessas regiōes não teriam sido geradas, ou apenas parte delas teria sido.

Por outro lado, em algumas regiões pobres, o crescimento populacional, nesses casos, $€$ indispensável para que elas cresçam economicamente. $O$ aumento do contingente populacional torna-se a única maneira delas entrarem num estágio superior da divisão do trabalho e de usufruirem dos padrões de consumo dos paŕses adiantados. Encontram-se num estágio no qual ainda não puderam povoar densamente seus territórios e explorar totalmente o potencial de seus recursos humanos e naturais e os benefícios da divisão do trabalho. Hayek diz que "não é moral, nem éti$\mathrm{co}$, nem justo e nem econômico a defesa do controle da natalidade indiscriminadamente". $O$ fato $\varepsilon$ que alguns paŕses adiantados querem fazer dos parses mais pobres "parques mundiais ecológicos", ou "pulmões do mundo", ao custo de sua pobreza.

As discussóes sobre o crescimento demográfico devem vir precedidas de um amplo entendimento econômico sobre as possibilidades do fator trabalho. Cada individuo é diferente do outro, no que tange à capacidade de aprendizado, gostos e interesse por cada assunto. Essa é a caracterfstica da diversidade do trabalho humano, fator fundamental na divisão do trabalho e no desenvolvimento econômico e social dos povos. A diferenciação faz com que cada elemento que nasça seja útil, em al- 
gum aspecto, aos demais. $O$ inventor do barbeador elétrico criou novas formas de se fazer a barba. Tornou-a mais fácil, mais simples e mais rápida. A humanidade, com certeza, beneficiou-se do nascimento desse criador. $O$ novo produto criou uma série de necessidades que passaram a ser satisfeias com o emprego de um amplo contingente populacional, quer no ensino, quer na fabricação do produto. Tornou possível a diferenciação dos indivíduos e de suas funções, através da divisão do trabalho produtivo o que os tornam diferentes uns dos outros em conhecimento, especialização, informação, inteligência, destreza, propriedade e renda. $E$ isso faz com que a humanidade possa manter-se viva. Como diz Hayek, "o aumento populacional cria possibilidades meramente inimagináveis... (aos homens da terra)".

Não se pode dizer, portanto, que o aumento populacional seja bon. ou ruim, num sentido absoluto. A questão tem de ser remetida para cada continente, para cada pals, para cada estado, para cada munićpio ou para cada pedaço de terra habitado pelo homem. Se, com o nfvel tecnologico e de conhecimento de seus habitantes, existir possibilidade de sobrevivência auto-sustentada, o aumento populacional $e$ bem-vindo. Só os habitantes de cada região têm condições de saber se é possível aumentar o número de seus habitantes ou não.

Mesmo assim, a questão não é simples. O aumento populacional tem sido patrocinado por auxflios espúrios que, em nome da moral, da ética, da religião e de outras tantas ćnicas e desinformadas manifestações, perpetuam as populações pobres no mundo, criando-lhes expectativas de abundância material, desvinculadas do trabalho criativo e produtivo.

\subsection{A Lei dos Pobres}

A lei dos pobres constituiu-se num fundo de assistência para amparar velhos, doentes e crianças pobres e necessitadas. Foi criada na Inglaterra, no final do século XV. Foi um grande equívoco no campo social. Não passou de mais uma maneira desinteligente de se tentar burlar a Lei Malthusiana, dando-se uma solução dita "moral" para um problema que requeria uma solução econômica. $O$ resultado de tal "assistência" foi um grande crescimento da população pobre. Nunca houve tanta pobreza, vagabundagem e mendicância, como na Inglaterra do final do século XV e ińrcio do XVI, época que se seguiu à promulgação da lei.

Durante o século XVI, sucederam-se leis e decretos tentando reduzir o número de pedintes e vagabundos nas cidades. Atingiram, porem, o efeito e não a causa do problema. Eram, ademais, consideradas leis desumanas, devido ao fato de punirem com penas severas os "crimes" de 
vadiagem. Em 1530, Henrique VIII criou uma lei dizendo que "doentes e velhos incapacitados têm licença para pedir esmolas, mas vagabundos sadios serão flagelados e encarcerados...". Sobre a "Lei dos Pobres" Thomas Malthus escreveu:

\footnotetext{
"Se, por lei, todo ser humano necessitado de ajuda estivesse certo de obtela, em grau suficiente para tornar sua vida relativamente confortável, poderfamos esperar que todos demais impostos seriam pequenos, comparados a taxa dos pobres... (tais leis) transformariam a riqueza em miseria". (Malthus, 1983, p.297).
}

A lei, ou taxa, dos pobres, tem sido citada como um dos principais registros da insensatez econômica. $O$ homem age de acordo com os estrmulos que se lhes oferecem. Quando thes indicam que "em se trabalhando dá, em não se trabalhando dão", e a previsão de receber é consistente, ele fica com a segunda opção. Essa é a lei maior da ação humana. Não se pode, porém, atribuir a culpa da ociosidade àqueles que aceitam as regras, mas aos que criam as regras.

A lei dos pobres, entretanto, não foi abolida até hoje. Foi, apenas, maquiada e introduzida com outros nomes, como, por exemplo, auxflionatalidade, "salário-famllia", entre tantas outras sandices econômicas.

\section{O PROBLEMA DEMOGRÁfico NO BRASIL}

\subsection{O Crescimento Populacional}

A forma de crescimento populacional no Brasil não foi diferente da dos demais parses do mundo: cresceu impulsionado mais pela queda da taxa de mortalidade, do que pelo aumento da taxa de fertilidade. Nos anos de 1860 , a população brasileira cresceu ao redor de $1,4 \%$ ao ano, fndice baixo, devido à alta taxa de mortalidade. Os avanços tecnológicos, as novas descobertas, principalmente no campo da medicina e das profilaxias, começaram a se fazer sentir no final dos anos de 1870. Dessa data em diante, os indices de mortalidade começaram a cair lentamente, mas de maneira consistente. Como a taxa de natalidade permanecia relativamente constante, o crescimento populacional começou a aumentar. De 1920 a 1940, o crscimento populacional foi de 1,9\% ao ano. Em 1940, a população brasileira era de 41.236 mil habitantes e a taxa de fecundidade, por mulher, de 6,16 filhos, proporção altíssima em relação aos dias de hoje, em torno de 3,15 filhos.

Alguns demógrafos dizem que o fndice ideal de reposição do contingente populacional é de 2 filhos por mulher. Outros discordam, alegando que nem todas as mulheres vão gerar filhos $\mathrm{e}$, com isso, pode haver decréscimo populacional. Economicamente, porém, a população de 


\section{um paŕs não deve ficar restrita à reposição do contingente populacional,}

mas às suas possibilidades econômicas.

A partir de 1940, o crescimento demográfico no Brasil começou a preocupar. De 1940 a 1950 , a população brasileira cresceu $2,33 \%$ ao ano. De 1950 a 1960 , o crescimento foi de $2,99 \%$, maior indice de crescimento populacional até hoje ocorrido na história do Brasil. Dessa data em diante, apesar da contínua redução da taxa de mortalidade, a taxa de crescimento populacional Íquida vem decrescendo, lenta, mas continuamente. De 1960 a 1970 , os índices foram de $2,89 \%$, de 1970 a 1980 , $2,48 \%$ e, de 1980 a $1990,1,89 \%$. De acordo com o IBGE, espera-se que chegue a $1,4 \%$ na última década do ano e baixe para $0,9 \%$ nas demais, conforme gráfico abaixo.

\section{TRANSIÇÃO DEMOGRÁFICA BRASILEIRA}
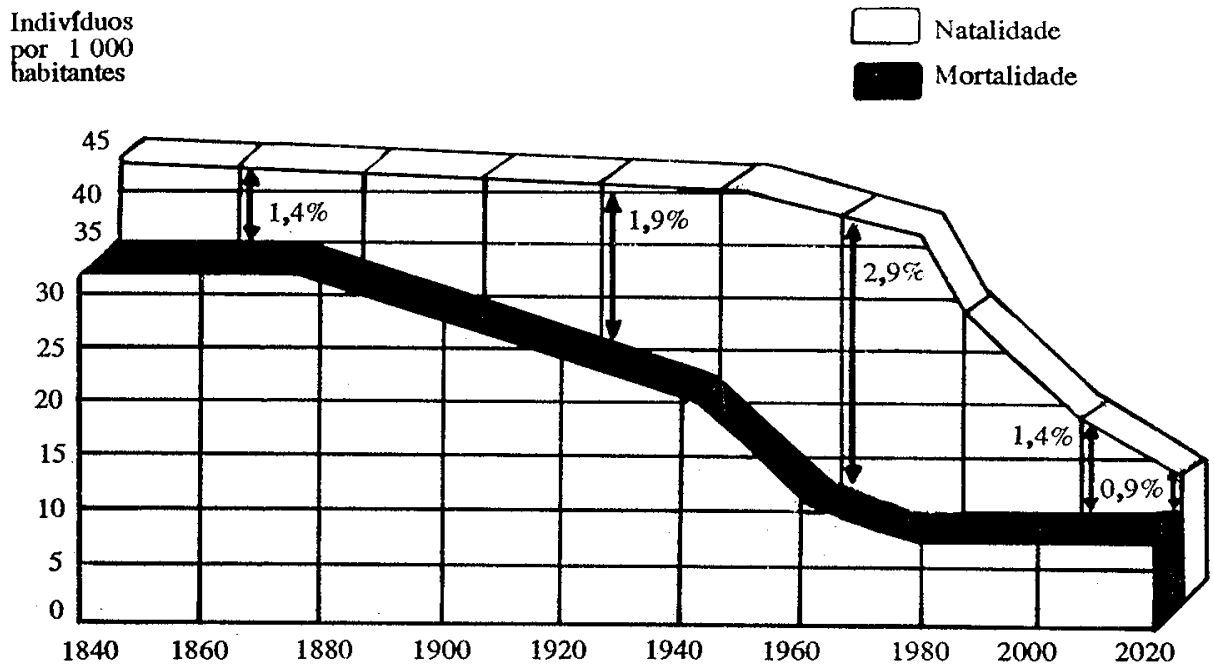

Fonte: População e desenvolvimento económico no Brasil. Thomas W. Merrick e Douglas H. Graham. Século XXI, a quantas andará a população brasileira. Ana Amélia Camarano, Ricardo Neupert e Kaizó Beltrão: $O$ mito da explosão demográfica. George Martine (Ciência Hoje. mar. 1989).

NOTA: A queda da mortalidade começa a se fazer sentir em torno de 1870 e se torna rıais nitida a partir de 1930, enquanto os índices de natalidade permanecem estáveis; a partir de 1970 as taxas de natalidade dimịuem drasticamente, permitindo projeçóes que näo confirmam os temores d e que o Brasil encontra-se diante de um quadro de explosáo demografica. 


\subsection{O Medo da Explosão Demografica no Brasil}

As preocupações com o crescimento demográfico brasileiro são fundamentadas em projeções que mostram que, na melhor das hipóteses, dentro de 20 anos o Brasil terá mais 60 milhões de habitantes. Quando se compara esse crescimento absoluto com a população atual do Chile (13,3 milhões), da Venezuela (19 milhões), da Bolfvia $(17,1$ milhões), da Argentina (33,4 milhões), do Peru (22 milhöes) ou, mesmo, com a de 1988 da França (55,8 milhões) da Grã-Bretanha $(57,1$ milhões) ou da Itália (57,5 milhōes), assusta-se ao se pensar que dentro de 20 anos teremos mais de uma França, mais de uma Grã-Bretanha ou mais de 20 Uruguais, que hoje tem cerca de 3 milhões de habitantes.

Esquecem que o dado relevante não é nem o crescimento populacional absoluto, nem o relativo. As comparações, ademais, de um aumento populacional futuro, com a população atual de outro paŕs, também não $\varepsilon$ um dado relevante. o fator relevante $\varepsilon$ o crescimento relativo da produçāo e da distribuição dos bens e serviços em cada paŕs, estado ou munićpio. Por exemplo, a renda per capita do Uruguai é semelhante à do Brasil. A questão, então, é saber qual a potencialidade econômica de cada pás, ou o quanto cada um vai crescer nos próximos 10 , 20 ou mais anos. Se o crescimento de renda per capita no Brasil for positivo e crescer mais do que no Uruguai, em qualquer perfodo aventado, o crescimento não se configura num problema, mas numa solução.

Todavia, a renda de um pars, principalmente de um pars pobre, e o resultado de uma média de regiões heterogêneas, umas ricas e outras pobres. $\mathrm{O}$ certo, portanto, $\varepsilon$ se verificar a distribuição da renda entre as diferentes regiōes do Paŕs, do Sul ao Norte, do Leste ao Oeste e, dentro dessas regiões, verificar-se a distribuição entre os Estados, dentro dos estados, entre os munićpios, e assim por diante. A regra final, embora dura e, às vezes, considerada inválida por outros conceitos não-económicos, é a de que nenhum individuo pode ser gerado se nāo for para ele gerar, individualmente, os recursos necessários para a sua sobrevivência. Tem-se de dar ênfase que a regra vale para os individuos ainda não gerados, e não para aqueles que já habitam a terra, mesmo que ainda se encontrem no ventre da mãe.

Se a regra fosse obedecida, não haveria pobreza no mundo, como as constantes do quadro abaixo: 


\section{TABELA 2 \\ BOLSŌES DE POBREZA NO MUNDO (1985)}

\begin{tabular}{lcrc}
\hline Regióes & $\begin{array}{c}\text { População } \\
\text { Total }\end{array}$ & Pobres* & $\%$ \\
\hline - Oriente Médio e Norte da África & 190 & 60 & 32 \\
- África (Sul-Saara) & 380 & 180 & 47 \\
- Ásia (Sul) & 420 & 100 & 24 \\
- Ásia (Oriental) & 350 & 70 & 20 \\
\hline
\end{tabular}

Fonte: Banco Mundial/The Economist

* Menos de US\$370 por ano

O critério acima, que estabelece como indivíduo pobre o mfnimo de US $\$ 370.00$ por ano, pode ser adaptado para o Brasil, sem se fazer a conversão de compra da moeda americana em cada pars. a "Pesquisa Nacional por Amostras de Domicnlios" de 1990 do IBGE levantou, no quadro abaixo, em salários mf́nimos reais, a distribuição dos rendimentos mensais da população brasileira. Embora tenha havido, no Brasil, um aumento da pobreza de 1981 a 1989. mesmo as faixas de renda de um salário mínimo mensal (cerca de US\$74.00 mensais e perto de US $\$ 1.000 .00$ ao ano), estão acima das faixas de pobreza estipuladas pelo Banco Mundial.

TABELA 3 ESTRUTURA DA DISTRIBUIÇĀO DE RENDA DA
POPULAÇĀO BRASILEIRA EM 1981 E EM 1989

\begin{tabular}{lrr}
\hline Salários-Mf́nimos & 1981 & 1989 \\
\hline Ate 1 & $16,0 \%$ & $19,6 \%$ \\
+ de 1 a 2 & $14,9 \%$ & $13,7 \%$ \\
+ de 2 a 5 & $15,1 \%$ & $15,5 \%$ \\
+ de 5 a 10 & $5,2 \%$ & $5,8 \%$ \\
+ de 10 a 20 & $2,0 \%$ & $3,1 \%$ \\
+ de 20 & $1,1 \%$ & $2,0 \%$ \\
S/Rendimentos & $45,4 \%$ & $39,9 \%$ \\
S/Declaração & $0,3 \%$ & $0,4 \%$ \\
\hline
\end{tabular}

Fonte: IBGE. Pesquisa Nacional por Amostras de Domicflios, 1990 
Isso não significa, contudo, que não existam miseráveis em nọsso Pars. Ao contrário, os dados são de que hâ mais de $\mathbf{3 0}$ milhōes de carentes no Brasil e de que cerca de nove milhões de crianças estão fora dos bancos escolares. O problema, tanto no Brasil, quanto na maior parte do mundo subdesenvolvido e em desenvolvimento, 6 que o aumento populacional é maior nas camadas da população mais pobre do que nas remediadas ou ricas e isso, alem de causar mal-estar geral, gera intranqüilidade social. $O$ Brasil, contudo, não ê diferente dos demais parses do mundo. $O$ que contém o crescimento demográfico nas regióes carentes e de baixa renda são os estímulos governamentais espúrios, patrocinados com os recursos dos contribuintes, na qual nunca deveriam ter sido acionados para essa finalidade.

\subsection{Os Estímulos à Pobreza no Brasil}

A exemplo do que se mencionou em níveis mundiais, os fatores econômicos, em qualquer pars, sempre foram os principais estimuladores do crescimento demográfico. O homem do meio rural sempre teve os filhos como uma força de trabalho e como uma forma de amparo na velhice. O trabalho dos filhos não so sempre supria o próprio sustento, como ainda se configurava numa garantia aos pais na velhice, quando não pudessem mais trabalhar. Os beneffcios afetivos de ser pai ou mãe são plenamente complementados com os benefícios financeiros, advindos do trabalho produtivo e previdenciário dos filhos.

Nas cidades, contudo, a situação muda de figura. Os filhos não mais são uma fonte de renda, nem de amparo à velhice, mas um custo muito alto na forma de alimentação, saúde, vestuário e educação. Estima-se, por alto, que o custo anual de um filho, a preços de hoje, de uma famflia de classe média alta, não fique em menos de US\$3.000,00 por ano, sem contar os gastos de férias e de diversão, nem o custo de oportunidade dos pais gasto com eles, que se configura em trabalho e que poderia ser dedicado a outras tarefas produtivas remuneradas. Esses fatores transformam os filhos em substanciais fontes de despesas de custeio nas grandes cidades e, dada maior mobilidade e afastamento familiar nas cidades, em muito pouco fator de investimento.

Hayek diz, de outra parte, que as pessoas que migram para as cidades e passam habitar as suas periferias, custam a assimilar as tradiçōes, costumes e formas de vida das cidades e continuam, por um perfodo de tempo, a adotar as formas de procriação do campo. Por isso, o crescimento populacional ainda se mantém por alguns anos principalmente nas periferias, nos períodos de migração do homem do campo para as cidades. Esse crescimento desordenado, porem, tende a acabar e, de acordo com Hayek, já está acabando. Cita as cidades do México, Cairo, Calcu- 
tá, Jacarta, Caracas, Lagos, Bombaim e São Paulo, onde a população mais do que dobrou em curto espaço de tempo, como exemplos de superação do impulso inicial de expansão demográfica que caracterizou o processo de industrialização no mundo. Cedo ou tarde os habitantes das periferias dessas cidades vão passar a ter uma famnlia em número condizente com o meio em que vivem, quando, entāo, vai-se obter o equilíbrio populacional.

De acordo com o Almanaque Abril, baseado em dados do IBGE, as legislações brasileiras também têm sido uma grande fonte de estímulo ao crescimento populacional. A Constituição de 1934 estabelecia: "Ao Estado cabe socorrer as famflias de prole numerosa”. Na Constituiçāo de 1937, foi mudado para "Às famílias numerosas serão atriburdas compensações na proporção de seus encargos". Na de 1946, "A lei instituirá o amparo às famílias de prole numerosa". Em 1963, pela Lei 4266, foi criado o "Salário Famflia", na proporção de $5 \%$ do salário mínimo para cada filho, até 14 anos de idade. As informações são de que essas medidas elevaram as taxas de crescimento a perto de $3 \%$ ao ano nos anos 50 e infcio dos anos 60. Esses estŕmulos, segundo o IBGE, "colocou o Brasil como um dos paŕses de maior crescimento no mundo".

Com o patrocínio de organismos internacionais (ONU e o Banco Mundial), foi criado, em 1964, a Sociedade Brasileira de Bem-Estar Familiar (BEMFAM) para atuar na área do planejamento familiar, cabendolhe a tarefa da distribuição de pflulas anticoncepcionais, de colocação de dispositivos intra-uterinos e da realização de ligaduras de trompas.

Os estŕmulos financeiros, todavia, que se configuraram no principal indutor do crescimento populacional, não foram retirados. Ainda temos muitas "leis dos pobres" no Brasil, que nada mais são do que estimuladores da geração de filhos. Temos absoluta convicção de que não se conseguirá grandes resultados no controle demográfico, sem a aboliçāo dos estímulos à geração de filhos.

Um fator, entretanto, tem sido citado como impeciho do funcionamento correto da ordem expontânea de mercado, no que tange ao limite do crescimento populacional. Trata-se do desconhecimento, por parte de um grande contigente de pobres, dos avanços medicinais e tecnologicos e que thes permitam manter relações sexuais sem ter filhos, tais como o conhecimento dos dias férteis da mulher, os contraceptivos intra-uterinos, as pílulas anticoncepcionais e as ligaduras de trompas (para as mulheres) e as vasectomias e preservativos (para os homens). Muitas pessoas ainda geram filhos não-planejados ou que não gostariam de ter gerados.

Tem-se de compreender que é fundamental, não só a disseminaçāo da educação sexual nas escolas do campo e das cidades, como a complementação, pela iniciativa privada, dos serviços praticados pela BEMFAM na área demografica, de forma a levar para o campo e demais luga- 
res onde hoje ela não opera, os trabalhos dessa Instituição, possibilitando, dessa maneira, a oportunidade de a população usar, se quiser, qualquer contraceptivo existente no mercado.

\section{CONCLUSĀO E SUGESTŌES}

As leis malthusianas são verdades as quais nenhum ser vivo pode escapar. Está fundamentada numa lei biológica maior: a necessidade do alimento para se viver. Malthus errou, porém, ao acreditar que a ação e a interação do homem na terra não levasse isso em conta. Se, até hoje, em n̊veis mundiais, não se tomou uma atitude mais drástica com relação ao crescimento populacional, foi porque não se precisou. Ao contrário, o homem se dá ao luxo de manter uma população paralela de animais domésticos, em números muitas vezes superiores às possibilidades de autoalimentação desses animais, devido à sobra de alimentos. A população da terra passou de 730 milhōes em 1750, para mais de 5 bilhões em 1990, mas a produção de alimentos cresceu mais ainda, ignorando, ao menos por ora, os predicamentos malthusianos.

$O$ Clube de Roma levantou a questão por outro ângulo. Foi buscar na exaustão dos recursos não renováveis, na poluição e na interação dos seres vivos com o seu meio ambiente, as dificuldades para a sobrevivência do homem na terra. Nesse contexto, a própria solução para o problema malthusiano, encontrada na produção intensiva de alimentos, não seria uma solução, mas um problema. Ao crescer, desordenadamente, o homem fere o seu "habitat" e, com isso, limita a própria sobrevivência na terra. O maior culpado, assim, dos problemas ecológicos, são os pafses ricos que, de acordo com o Relatório do Banco Mundial de 1991, mantêm $20 \%$ da população mundial, mas fabrica $75 \%$ de sua produção e é responsável por mais de $75 \%$ do comércio realizado no mundo, além de responder por quase a totalidade das exportaçōes de capital e de tecnologia.

Todavia, tanto o modelo malthusiano, quanto o do Clube de Roma, são modelos exponenciais simples, que não levam em conta hipóteses dinâmicas de adaptação do homem ao meio ambiente, de acordo com as expectativas futuras que se lhes apresentam. Os avanços da medicina e as descobertas dos contraceptivos são uma clara demonstração da ação humana bloqueadora do crescimento populacional. Aliás, o crescimento populacional deixou de ser um problema nos parses ricos, para ser uma solução. O crescimento populacional, porém, ainda $€$ um problema em alguns parses pobres. Esse problema, entretanto, s 6 vai ser resolvido se for estudado em níveis regionais. Se for feita uma profunda investigação sobre as reais causas da fome na Somália, em grande parte do Nordeste brasileiro e de outras regiōes do Brasil e do mundo, vamos encontrar a 
resposta para o animal homem não parar de procriar em épocas de crise: os subsílios internos e externos, geralmente feito por regiōes ricas ou parses ricos, que criam perspectivas de vida futura, em lugares muitas vezes sem perspectiva de vida nenhuma. A mais insensata legislação conhecida na históia, foi a "Lei dos Pobres", criada na Inglaterra com a pretensão de ajudar os pobres e desempregados e que foi responsável pela geração do maior contigente de miseráveis naquele Pafs. Até hoje não foi totalmente abolida. Ainda pode-se encontrá-la, maquiada, e com diferentes nomes e pretensões, em todo mundo.

A ação humana é direcionada, basicamente, para aumentar um conforto ou reduzir um desconforto. Os estŕmulos e os desestŕmulos econômico-financeiros são peças fundamentais nesse processo. Quando um ato constitucional diz que o governo deve ajudar as famflias de prole numerosa, como sempre aconteceu nas constituições brasileiras, ele acaba com as dificulades e incertezas da famflia e promove o crescimento populacional. Da mesma forma, quando se cria uma lei que premia a geração de filhos com $5 \%$ do salário mínimo, como a que instituiu o "salário famflia" no Brasil, nada mais faz do que induzir à geração de filhos... pobres.

A questão demográfica tem de ser enfrentada, antes de mais nada, pela revogação das legislações que estimulam a geração de filhos. Depois, pela criação de estŕmulos às famflias com um único filho e de desestŕmulo às de prole numerosa. Essa ação poderia ser complementada com um trabalho sério de educação sexual nas escolas e com o engajamento da inicitiva privada, incentivada via redução de impostos, na distribuição de contraceptivos em todos os lugares do Brasil, principalmente nas regiões mais pobres e com maior taxa de fecundidade. Caberia, ademais, a ampliação dos serviços desenvolvidos pela BEMFAM, não só na inclusão de novos tipos de serviços (inclusive na distribuição de contraceptivos) como na extensão de suas redes prestadoras de serviços.

\section{BIBLIOGRAFIA}

GILDER, George. Health and Poverly. New York: Bentam Books, 1982.

HAYEK Friedrich A. The Fatal Conceit. The Errors of Socialims". London: Routledge, 1990.

MALTHUS, Thomas Robert. Bnsaios Sobre a Populaç̆o. São Paulo: Abril Cultural, 1983.

MEADOWS, Dennis L. e Outros. The Limits to Growth. A Reporf or the Club of Rome's Project on the Predicament of Mankind. New York: A Potomac Associates Book, 1974.

MISES, Ludwig Von. A grio Humann. Rio de Janeiro: Instituto Liberal, 1990.

NORTH, Douglass C. \& MILLER, Roger Leroy. The Economics of Public Issues. 3ed. New York: Harper and Row, Publishers, 1976. 


\title{
PERINGER, Alfredo Marcolin. Monctarismo ve Keynesinnismo ve Eetruturalism.In- flaçto, Desemprego e Taxas de Juros. Rio de Janeiro: Glo o, 1989. Economia Heterodora x Bconomia Ortodoxa. Porto Ale re: Ortiz, 1989.
}

\begin{abstract}
This work deals with the demographic callange presented by Thomas Malthus and Club of Rome thesis and recognize the incontest truth in both theories. There is an agreament with these thesis in the way that there is a limit to live in this earth that is imposed by the basic food to feed the people. On the other hand, by the study of praxeology, science of the human action, we know we will never reach malthusia for Club of Rome predicaments. The desequilibrium that exist between the quantity of food and population in some regions of the earth is the result of the desfiguration of the human action promoted by internal and external subsidies that are largelly a promotion of procreation. Without the banishment of these subsidies and other stimulus of procreation we will never reach the population's equlibrium and will never eliminate the poverly of the earth.
\end{abstract}

